\title{
AMBIÊNCIA DA PEDIATRIA: \\ produção de subjetividades nas crianças internadas
}

\author{
AMBIENCE OF PEDIATRICS: \\ production of subjectivities in hospitalized children
}

\section{Juliane Portella Ribeiro', Adriane Maria Netto de Oliveira', Giovana Calcagno Gomes², Maira Buss Thofehrn ${ }^{3}$, Marina Soares Mota ${ }^{4}$}

\section{RESUMO}

Objetivo: Investigar os reflexos da ambiência da unidade de pediatria na produção de subjetividades nas crianças internadas, segundo a perspectiva dos profissionais de enfermagem. Metodologia: estudo descritivo e exploratório com abordagem qualitativa realizado com 20 profissionais de enfermagem atuantes nas unidades de pediatria de dois Hospitais Universitários. A coleta de dados ocorreu por meio de entrevistas semiestruturadas, organizadas e tratadas pelo software Nvivo 10. Resultados: os profissionais de enfermagem apontam que desde a entrada na Unidade de Pediatria há a produção de subjetividades nas crianças, sendo percebida por eles por meio de reações de estranhamento ao ambiente quedificultam a interação com elas, bem como a realização das ações de cuidado. Conclusão: faz-se necessário lançar mão de aspectos humanos como acolhimento, receptividade, calma, carinho e atenção, de forma a contribuir para que a criança perceba o ambiente hospitalar e os profissionais de enfermagem de forma menos traumática e agressiva.

Descritores: Ambiente de Instituições de Saúde; Humanização da Assistência; Pediatria; Criança Hospitalizada; Enfermagem.

\section{ABSTRACT \\ Objective: Investigating the reflexes of ambience of the pediatric unitin the production of subjectivities in hospitalized children, from the perspective of nursing professionals. Methodology: Descriptive, exploratory and qualitative study conducted with 20 nursing professionals working in the pediatric units of two university hospitals. The data were collected through semi-structured interviews, organized and handled by software Nvivo 10. Results: The nursing professionals point out that since the en tryin the Unit of Pediatrics there is the production of subjectivity in children, being perceived by them through estrangement actions to the environment that difficult the interaction with them, as well as the realization of care actions. Conclusion: it is necessary to make use of human aspects as host, welcome, receptivity, calm, affection and attention in order to help the child perceives the hospital and the nursing professionals form less traumaticand aggressive.}

Descriptors: Health Facility Environment; Humanization of Assistance; Pediatrics;

Child Hospitalized; Nursing.
${ }^{1}$ Doutora em Enfermagem pela Universidade Federal do Rio Grande (FURG), Rio Grande, RS, Brasil.

${ }^{2}$ Doutora em Filosofia da Enfermagem pela Universidade Federal do Rio Grande (FURG), Rio Grande, RS, Brasil.

${ }^{3}$ Pós-Doutora em Enfermagem pela Universidade Federal de Pelotas (UFPEL), Pelotas, RS, Brasil.

${ }^{4}$ Doutoranda em Enfermagem pela Universidade Federal do Rio Grande (FURG), Rio Grande, RS, Brasil. 


\section{Introdução}

A criança ao entrar no ambiente hospitalar, além de ter de lidar com o malestar provocado pela enfermidade, é afastada de seu ambiente familiar, de seus amigos, da escola e de seus objetos pessoais. Na maioria das vezes, 0 ambiente hospitalar está organizado em função da cura da doença, semplanejamento para atender à individualidade de cada criança e as necessidades globais da infância'.

0 ritmo monótono e repetitivo, devido a suas regras e rotinas, faz com que o ambiente hospitalar se difira do cotidiano ativo da criança, com atividades escolares, brincadeiras e esportes ${ }^{2}$. Trata-se de um ambiente que impõe mudanças a serem assimiladas por ela, como interagir com pessoas desconhecidas; realizar exames e intervenções que poderão ser dolorosas ou desagradáveis; repouso obrigatório; utilização de medicamentos e aparelhos; horários diferentes ao da sua rotina para realização de atividades diárias de alimentação e higiene; ruídos e outros incômodos ${ }^{3}$.

A enfermagem, por manter contato próximo e contínuo, realiza cuidados relacionados às necessidades básicas das crianças, como banho e alimentação, outros voltados à terapêutica, como a verificação de sinais vitais, administração de medicamentos e, ainda, procedimentos considerados invasivos. Quando essa prática é realizada de forma impessoal, sem tratar a criança como um indivíduo com necessidades relacionadas à sua fase de desenvolvimento, pode contribuir para que a experiência da hospitalização seja percebida como estressante e traumática'.

Pelo fato da Unidade de Pediatria constituir-se espaço vital durante dias, semanas ou meses, a vivência de experiências estressantes pode levar a criança a reconhecê-la como ambiente de dor e sofrimento ${ }^{4}$. Nesse sentido, trabalhar a ambiência emerge como possibilidade de subsidiar a prática dos profissionais de enfermagem desse setor, uma vez que se refere ao tratamento dado ao espaço físico, social, profissional e de relações interpessoais, visando à produção de subjetividades, por meio de alguns elementos que atuam como modificadores e qualificadores do espaço ${ }^{5}$.

Diante do exposto, o presente estudo teve por objetivo investigar os reflexos da ambiência da unidade de pediatria na produção de subjetividades nas crianças internadas, segundo a perspectiva dos profissionais de enfermagem.

\section{Metodologia}

Trata-se de um estudo descritivo e exploratório com abordagem qualitativa dos dados, vinculado a Tese de Doutorado intitulada "A ambiência como ferramenta de humanização da unidade de pediatria: contribuições da enfermagem", apresentada ao Programa de Pós-Graduação em Enfermagem da Universidade Federal do Rio Grande (PPGENF/FURG).

Os ambientes investigados foram as unidades de pediatria de dois Hospitais Universitários do Sul do Brasil. A escolha destas instituições foi motivada pelo fato de serem referência de atendimento à população da micro e macrorregião sul do Rio Grande do Sul, além de possuírem semelhanças históricas em relação à origem, envolvimento com ensino, pesquisa, extensão e assistência à saúde.

Participaram do estudo 20 profissionais de enfermagem (com representantes de diferentes turnos de trabalho: manhã, tarde e noite), sendo dez de cada ambiente investigado. A seleção dos participantes foi intencional, de acordo com os critérios de inclusão e objetivos do estudo. Os critérios de inclusão foram: ser enfermeiro, técnico ou auxiliar de enfermagem, atuante na unidade de pediatria há pelo menos seis meses. Foram excluídos do estudo profissionais de férias ou licença saúde no período da coleta dos dados.

Com vistas a garantir os princípios éticos relativos a pesquisas que envolvem seres humanos, os sujeitos selecionados foram incluídos no estudo, somente, após manifestarem sua concordância em participar do mesmo, através da assinatura do Termo de Consentimento Livre e Esclarecido (TCLE). Além disso, o anonimato dos participantes foi preservado por meio do emprego da letra $\mathrm{P}$, sucedida do número da entrevista e instituição hospitalar pertencente, Hospital A (HA) ou Hospital B (HB).

A coleta de dados ocorreu no segundo semestre de 2014, por meio de entrevistas semiestruturadas, pois esta abordagem permite que 0 entrevistador coloque-se 0 mais próximo possível da perspectiva do entrevistado ${ }^{6}$. Foram questionados acerca dos reflexos da ambiência da Unidade de Pediatria na produção de subjetividades nas crianças internadas. Para preservar o conteúdo original e aumentar a acurácia dos dados obtidos, as entrevistas foram capturadas por um gravador de áudio. Os dados foram organizados e tratados por meio do software Nvivo 10, programa que auxilia na análise de material qualitativo, com ferramentas de codificação e armazenamento de textos em categorias específicas ${ }^{7}$. 
Os preceitos éticos da realização de pesquisa envolvendo seres humanos, conforme a Resolução $n^{0} 466$, de 12 de dezembro de $2012^{8}$. O projeto foi encaminhado ao Comitê de Ética em Pesquisa e aprovado mediante o Certificado de Apresentação para Apreciação Ética (CAEE) n³ 31172914.6.0000.5324, recebendo parecer favorável para sua publicação sob Parecer $n^{0} 85 / 2014$.

\section{Resultados}

A seguir apresentou-se a caracterização dos participantes do estudo e a categoria produção de subjetividades nas crianças internadas.

\section{Caracterização dos participantes do estudo}

Participaram deste estudo 20 profissionais de enfermagem predominantemente do sexo feminino, sendo 18 mulheres e dois homens, com idades que variam entre 35 e 55 anos, a maioria entre 45 e 55 anos ( $n=11 ; 55 \%)$. Destes, dez são enfermeiros, cinco são técnicos e cinco são auxiliares de enfermagem; cujo tempo de atuação na unidade de pediatria variou entre seis meses e 23 anos, com média de sete anos de atuação.

\section{Produção de subjetividades nas crianças internadas}

Os profissionais de enfermagem apontaram que desde a entrada na unidade de pediatria há a produção de subjetividades nas crianças, sendo percebida por eles por meio de reações de estranhamento ao ambiente. As crianças apresentam-se estressadas, chorosas, agressivas e arredias no momento da internação.

Pode-se dizer que chegam com pânico e estranham muito. As crianças de dois, três anos para cima chegam receosas. Às vezes, chorando e dizendo que não querem ficar (P1_HA);

A criança quando está internando fica mais estressada, arredia, agressiva, mas tudo isso é consequência do estranhamento com o ambiente. Sentem medo, choram (P3_HB).

Tais reações ocorrem em função da criança, na maioria das vezes, ainda não possuir maturidade suficiente para compreender a situação e a necessidade da internação e do tratamento. Consequentemente, associa 0 ambiente da Unidade de Pediatria e os profissionais de saúde com sensações dolorosas.

A internação da criança é sempre dramática. Ela nunca está preparada. Fica com medo da gente, por ver o branco do jaleco já se assusta. Para dar menos medo, às vezes, entramos sem o jaleco (P6_HB);

Geralmente, as crianças quando estão doentes ficam agressivas. Tu chegas perto e elas ficam em pânico, porque sabem que talvez vamos Ihes proporcionar alguma dor ou desconforto. Não entendem a necessidade de estarem ali (P1_HA).

Por esta razão, os profissionais referiram que a recepção e 0 acolhimento da criança no ambiente hospitalar possuem extrema importância para que ela sinta-se protegida e perceba a Unidade de Pediatria e as rotinas de tratamento de forma menos traumática e agressiva.

A recepção é importante para a criança se sentir protegida. Se chegar na unidade e não tiver uma boa recepção pode perceber a internação como uma coisa ruim, e aí o tratamento todo vai ser prejudicado (P4_HB);

A coisa mais importante é a recepção. Dependendo da maneira que tu tratas a criança na hora que chega [...], às vezes, a pessoa é um pouco mais áspera na maneira de falar, um pouco mais rígida e eles sentem. Isso prejudica. Depois tu queres chegar e não tens como (P8_HB). 
As crianças são sensíveis à forma como os profissionais interagem com elas. Logo, estabelecem sua relação a partir de suas percepções acerca de tal interação. Podendo ser uma relação de abertura quando o profissional de enfermagem à cativa e demonstra-se empático. Ou, uma relação de distanciamento, com dificuldades para manejá-la, quando o profissional apresenta-se emburrado e mal humorado.

[...] quem trabalha com crianças não pode entrar aqui emburrado, malhumorado no momento que tu tens o contato com a criança. Tem que lidar com a criança de outra maneira, se não a criança não vai se abrir para ti (P7_HA);

Tem que cativar a criança. Tu consegues fazer tudo que tu quiseres com a criança se tu conseguires cativar ela. Se tu és muito rígida, chegasna criança e ela não te deixa fazer nada, não te deixa nem ver os sinais vitais. Então, tens que ter aquela empatia (P10_HB).

O cuidado à criança hospitalizada transcende as habilidades técnicas da profissão de enfermagem, envolvendo características humanas que potencializam a relação de cuidado, como receptividade, calma, carinho e atenção.

Tem que ter esse jeitinho, esse carinho, faz parte do cuidado. Todo esse processo de ir e conversar bastante. Não pode chegar e já querer ir fazer um procedimento e deu. Não! Tu tens que chegar com jeito, com calma (P1_HA);

[...] mais atenção com as crianças, com os pais, porque não basta tu só fazeres a medicação. É mais do que isso. Acredito que o cuidado é mais do que ir lá e dar o antibiótico (P3_HA);

Se tu chegares só no profissional, ou fizeres sem avisar, sem dares um sorriso, a pessoa já fica diferente. A recepção é outra (P1_HB);

A gente tem que procurar fazer o nosso serviço, mas acho que tem que ser com carinho. A gente tem que procurar agradar, fazer carinho, porque criança é criança,[...] tens que dar um pouquinho de atenção (P7_HB).

Os profissionais reconhecem que o ambiente hospitalar e a rotina imposta por ele, com novos horários para alimentação, convívio com pessoas desconhecidas e com hábitos diferenciados, realização de procedimentos e medicações é estressante para qualquer pessoa. A criança pode entender essa situação como uma agressão pelo fato de ainda estar em processo de desenvolvimento e, muitas vezes, não possuir a maturidade suficiente para compreender o que está ocorrendo.

É um ambiente estressante. A criança, às vezes, muda seus hábitos de alimentação, de sono. Eu acho que isso atrapalha um pouco, muda a rotina. A hospitalização para qualquer pessoa é marcante (P10_HA);

Tem medicação toda hora, injeção, pessoas estranhas. Tem que distrair, é um ambiente estranho, é gente estranha e isso tudo pode ser sentido como uma agressão (P7_HB);

O fato de ficar internado muda a rotina. Ter que conviver com pessoas estranhas, com hábitos diferenciados. Nós profissionais ascendemos asluzes durante a noite, verificamos sinais, fazemos medicação, tocamos na criança. Alguns procedimentos são dolorosos e percebidos como uma agressão à criança. Até a nebulização pode tornar-se uma agressão, todas essas coisas que mudam a rotina delas (P2_HB).

Ressaltam, ainda, a importância em identificar mudanças no comportamento da criança em função da realização de sucessivos procedimentos invasivos e dolorosos.

Se a criança é extremamente manuseada, se estão sendo feito muitos procedimentos, ela pode se tornar uma criança mais irritada, chorosa. Então, isso ai a gente tem que atentar, porque, às vezes, é questão de dor, de manuseio ( $P 2$ _HA). 
Ao longo da hospitalização, os profissionais indicaram que a criança passa a compreender melhor o tratamento e a situação, podendo adotar um comportamento amigável com os profissionais que the prestam cuidados.

Quando a gente chega para conversar, para brincar, elas no início são receosas. Algumas com o tempo vão cedendo e acabam ficando amigas (P2_HB);

[...] depois, quando ela vai te conhecendo, todo aquele universo vai se abrir para ela ver como as coisas funcionam e aí pode até virar tua amiga, mas no começo é sempre difícil (P3_HB);

Elas ficam meio receosas. No primeiro momento elas não querem que chegue perto. Para tratar com a criança, para puncionar, qualquer procedimento invasivo que vá fazer, mas depois elas se adaptam e parecem não ter mais medo, brincam, correm pelo corredor, e conversam com a gente (P9_HB).

Para tanto, a brinquedoteca ou a sala de recreação mostram-se essenciais na rotina da Unidade de Pediatria, pois as brincadeiras desenvolvidas nesse espaço distraem e relaxam a criança, tornando o ambiente hospitalar menos estressante e traumático.

Eles estão num ambiente estranho. Às vezes, é traumático ficar aqui. Tem que ter uma recreação para a criança se distrair, não ficar só naquele ambiente (P7_HB);

A gente tem uma recreacionista que faz as brincadeiras, que proporciona relaxamento e torna o ambiente menos pesado (P2_HA);

[...] ela se desliga um pouco daquilo, esquece um pouco que está no hospital, ela não fica com medo (P8_HB);

Eu acho que relaxa a criança, quebra um pouco o medo do ambiente, dos profissionais. Então, ela sabendo que ali tem alegria, tem brinquedos, tem diversão, ela fica menos estressada no hospital (P3_HB).

Da mesma forma, as ações realizadas por voluntários desenvolvidas na Unidade de Pediatria transformam a rotina hospitalar e proporcionam às crianças e seus familiares um ambiente aconchegante e receptivo.

Esses profissionais do teatro e da música quebram a rotina deles, trazem o mundo da criança para dentro do hospital e tudo fica mais leve (P6_HA);

[...] quando os palhaços passam aqui tu percebes a diferença no comportamento das crianças e das mães. As crianças ficam mais receptivas, as mães ficam mais tranquilas. Então, eu acho que um ambiente que propicie momentos de lazer, momentos felizes, como a hora do conto, com brinquedos, com palhaço, muda bastante essa percepção da mãe e da criança a respeito do ambiente e do contato com o outro (P2_HB).

A brinquedoteca e a sala de recreação em conjunto com as ações voluntárias constituem-se em oportunidade para a criança ser criança, expressar-se de acordo com sua idade e interagir com as demais crianças hospitalizadas, o que Ihes proporciona momentos de alegria.

Para as crianças a brinquedoteca é imprescindivel, porque é o lugar em que elas se sentem mais felizes (P3_HA);

Válvula de escape, único momento de ser criança. Único momento que eles têm para serem criança e socializar com outras crianças (P4_HA);

Eles adoram interagir, principalmente com teatro e música. No olho tu notas o brilho (P6_HA); 
Tem criança que está há muito tempo aqui e está sofrida, a mãe está muito sofrida. Às vezes, o pouco que eles têm de alegria é quando esses profissionais chegam, porque eles cantam, distraem (P1_HA).

Por preservar aspectos do mundo infantil dentro do ambiente hospitalar, os profissionais de enfermagem consideram que esses espaços e ações auxiliam, não só na mudança de comportamento, como também, na melhora do quadro clínico das crianças.

Eles adoram a sala de recreação, têm paixão. O humor deles melhora muito e eles se recuperam mais rápido. Isso eu noto no dia a dia (P5_HA);

O palhaço e a ajudante, melhoram o sorriso, melhoram a autoestima deles. Os pais também ficam motivados (P8_HA);

[...] um momento que eles têm para brincar. Quando eles estão melhorzinhos, voltam a querer se divertir na sala de brinquedos, ter contato com outras crianças, melhoram em termos de saúde, ficam mais alegres (P8_HB).

No entanto, o horário restrito de funcionamento da brinquedoteca acarreta ansiedade e expectativa de poder usufruir do espaço e dos brinquedos.

A gente tem uma brinquedoteca que tem horários e dias especificos para funcionar. Eles ficam muito ansiosos, esperando esse dia e hora para brincar. Então, eu acho para a humanização acontecer esse ambiente para criança se divertir não podia ser restrito (P3_HB);

Quando eles dão uma melhoradinha eles querem a brinquedoteca, mas não abre pela manhã porque não tem quem cuide. As crianças ficam com a maior expectativa para a tarde poder brincar nesse espaço (P7_HB).

Diante disso, os profissionais suscitam a contratação de um profissional específico para a recreação, de forma a proporcionar às crianças um horário mais amplo de convívio com o universo infantil.

Eu entendo que precisa ter uma pessoa para cuidar dos brinquedos, mas eu acho que o hospital tinha que contratar um profissional só para isso, porque faz falta no convívio das crianças (P3_HB);

Acredito que a sala de recreação teria que ter a recreacionista num horário mais amplo (P5_HA).

Também, adaptações na estética da pediatria se fazem necessárias, no sentido de caracterizá-la como unidade específica ao tratamento de crianças. Os profissionais indicaram que pinturas coloridas e brinquedos, possibilitam a criança reconhecer que o hospital, mesmo sendo um ambiente de tratamento à saúde, pode ser um ambiente alegre $\mathrm{e}$ Ihes ofertar momentos de felicidade.

Quando eu penso em pediatria, tem que ser colorido, tem que ter espaço para as crianças brincarem. Eu penso que o ambiente tem que ser diferente do resto do hospital. A criança não pode se sentir entrando no hospital. Ela tem que saber que ela veio tratar a saúde, mas que o ambiente é alegre (P3_HB);

[...] tornar o ambiente alegre e colorido, que não lembrasse um hospital, que fugisse daquela imagem que tu tens do hospital que é a parede branca, o cheiro, a roupa das pessoas, que é aquela coisa assim formal, que fugisse disso e lembrasse um momento de alegria e de felicidade. A Unidade de Pediatria é um lugar que tem coisas ruins, mas também tem coisas boas (P1_HA). 


\section{Discussão}

Os resultados apontam que as crianças ficam receosas ao entrarem na Unidade de Pediatria e manifestam reações de pânico e estresse, demonstrando-se chorosas, agressivas e arredias. Tais reações ocorrem, na maioria das vezes, pelo fato da criança ainda não possuir maturidade suficiente para compreender sua doença, necessidade de tratamento e hospitalização. Além disso, o consequente afastamento de sua rotina, em que objetos, atividades e pessoas são retirados de seu convívio, contribui para que associe o hospital e o profissional de saúde a uma vivência triste e com sensações dolorosas.

Aeste respeito, estudo realizado com o objetivo de compreender a hospitalização pelo olhar da criança e do adolescente constatou que ela é percebida como uma experiência estressante por causar agravos emocionais, expressos como tristeza, sensação de prisão, saudade de casa, falta dos amigos, dos irmãos, dos parentes e impossibilidade de brincar ${ }^{9}$. Por esta razão, 0 acolhimento da criança no ambiente hospitalar é evidenciado como extremamente importante para que ela sinta-se protegida e perceba a pediatria e as rotinas de tratamento de forma menos traumática e agressiva.

Acolhê-la pressupõe a oferta de um ambiente confortável, cuja disposição promova a interação das crianças com os profissionais de enfermagem de maneira não intimidadora ${ }^{5}$, propiciando à criança manifestarsuas ansiedades e necessidades . O cuidado à criança envolve atentar, para além dos aspectos clínicos, para um ser com inúmeras possibilidades de existência, que carrega consigo experiências e vivências, urdidas de emoções, sentimentos, paixões, sonhos e utopia ${ }^{10}$.

As crianças são sensíveis à forma como os profissionais de enfermagem interagem com elas. Logo, estabelecem sua relação a partir de suas percepções acerca de tal interação, aceitando ou não os cuidados ofertados pelos mesmos. Nesse sentido, pesquisa avaliativa sobre qualidade dos cuidados de enfermagem, realizada com crianças e adolescentes hospitalizados, apontou que os comportamentos adotados pelas enfermeiras influenciavam positiva ou negativamente a percepção da qualidade do cuidado ofertado. Os comportamentos avaliados positivamente foram aqueles que fizeram os respondentes sentirem-se bem, confortáveis, felizes e seguros, pois a enfermeira atendeu às suas necessidades quando precisaram dela, além de avaliá-los frequentemente, administrar medicamentos, ser amigável e escutá-los. Os comportamentos indicados como negativos foram os que fizeram eles se sentirem tristes, mal, com medo e irritados, incluindo acordá-lo e realizar procedimentos que ferem ou são desconfortáveis ${ }^{11}$.

O cuidado à criança hospitalizada transcende as habilidades técnicas da profissão de enfermagem, envolvendo características humanas que potencializam a relação de cuidado, como receptividade, calma, carinho e atenção. De forma semelhante, estudo realizado com o objetivo de identificar a percepção da equipe de enfermagem sobre a humanização no cuidado assinalou que cuidar de forma humanizada ocorre ao olhar a pessoa como um todo, abrangendo o olhar holístico, o acolhimento, a relação de vínculo e a comunicação ${ }^{12}$.

Considerando que mesmo hospitalizada a criança não perde suas características infantis, aponta-se a brinquedoteca e a sala de recreação como espaços essenciais à Unidade de Pediatria, pois a possibilita sair do leito, sair da enfermaria e brincar, distraindo-se das rotinas hospitalares. Assim, coloca-se como uma ferramenta capaz de amenizar as mudanças provocadas pela hospitalização e aproximar a criança do universo infantil, tornando o ambiente menos estressante e traumático.

Pesquisadores concluíram que a atividade lúdica possibilita a criança melhor adaptação e familiarização ao hospital, visto que ela pode manipular imaginariamente o ambiente e aproximar-se da realidade cotidiana, ou transformar a situação vivenciada em algo agradável e familiar ${ }^{13}$. O brincar durante a internação hospitalar constitui-se em um momento em que a criança apropria-se do espaço, preenchendo-o com suas fantasias, experimentado seus limites de tolerância, para encontrar e desenvolver estratégias de enfrentamento ao sofrimento, à dor e à doençca ${ }^{14}$.

Os resultados do presente estudo apontaram que a brinquedoteca e a sala de recreação em conjunto com as ações voluntárias caracterizam a pediatria como espaço próprio para o tratamento de crianças, oportunizando as mesmas serem crianças, expressarem-se de acordo com sua idade e interagirem entre si, proporcionando-lhes momentos de alegria e diversão. Além disso, modificam a rotina hospitalar, tornando o ambiente mais leve e, consequentemente, deixando às crianças e seus familiares mais tranquilos e receptivos às ações de cuidado.

Pesquisa realizada com o objetivo de descrever a percepção da criança, acerca do lúdico no ambiente hospitalar destacou que a brinquedoteca é representada como um lugar de socialização, onde se pode resgatar momentos vivenciados no cotidiano normal por meio do brincar com outras crianças ${ }^{13}$. Ao assegurar à criança 0 direito de brincar e estimulá-la a processos de socialização com as demais, as atividades lúdicas desenvolvidas na Unidade de Pediatria transformam o aspecto triste da internação em momentos alegres, favorecendo as condições para sua recuperação ${ }^{14}$. 
A criança revela por meio do brincar seu aspecto saudável, pois, tem acesso a uma linguagem de seu domínio, o que a possibilita elaborar a experiência de adoecimento e hospitalização, transpondo as limitações impostas pelas mesmas ${ }^{15}$. Assim, é possível estabelecer relações em saúde que não sejam pautadas no assujeitamento da criança à normatividade que é colocada sobre a concepção de saúde: regras e um estilo de vida que a impedem de agir de maneira infantil, própria a sua idade. Ao apostar na sua capacidade de expressão e compreensão, permite-se a criança a manifestação de sua subjetividade, bem como ser uma protagonista no enfrentamento da doença e da hospitalização.

De acordo com os entrevistados, ao preservarem-se aspectos do mundo infantil no ambiente hospitalar, contribuise para que as crianças não se percebam como doentes e, em função disso, expressem comportamentos próprios à idade. Fato que leva os profissionais de enfermagem a considerarem que a busca por essas atividades constitui-se em um indicativo de melhora do seu quadro clínico. Nesse sentido, estudo com o objetivo de compreender a influência do ambiente do hospital em crianças hospitalizadas indicou que esse influencia no desfecho do processo de produção de saúde, pois, quando a criança sente que a Unidade de Pediatria é feita para ela a mesma se envolve ativamente no tratamento e adota novos hábitos².

Para ampliar as alternativas lúdicas e respeitar a individualidade das crianças, os entrevistados sugerem estender o horário de funcionamento da brinquedoteca e sala de recreação, assim reduzindo a ansiedade gerada nas crianças pela expectativa de poder usufruir do espaço, bem como, melhorar a estética da pediatria no sentido de caracterizá-la como unidade específica ao tratamento de crianças.

\section{Considerações Finais}

Os profissionais de enfermagem apontam que desde a entrada na Unidade de Pediatria há a produção de subjetividades nas crianças, sendo percebida por eles por meio de reações de estranhamento ao ambiente que, consequentemente, dificultam a interação com elas, bem como a realização das ações de cuidado. Portanto, faz-se necessário lançar mão, além dos aspectos técnicos da profissão, de aspectos humanos como acolhimento, receptividade, calma, carinho e atenção, de forma a contribuir para que ela sinta-se protegida, percebendo o ambiente hospitalar e os profissionais de enfermagem de forma menos traumática e agressiva.

Ademais, referiram como importante proporcionar espaços como a brinquedoteca, a sala de recreação e 0 envolvimento em ações desenvolvidas por voluntários que distraem a criança das rotinas hospitalares para melhorar os reflexos da ambiência da unidade de pediatria na produção de subjetividades nas crianças internadas. Nesses espaços a criança pode não se perceber como doente e manifestar sua subjetividade como criança, brincando e interagindo com as demais crianças. Assim, torna-se possível estabelecer relações em saúde que não sejam pautadas pelo assujeitamento da criança às rotinas hospitalares que a impeçam de agir de maneira infantil.

Adequar a ambiência da Unidade de Pediatria às necessidades das crianças e aproximá-la do universo infantil apresenta-se como uma importante ação em saúde, uma vez que poderá contribuir para que a criança possa perceber esse ambiente e os profissionais de enfermagem de forma positiva, podendo manifestar livremente suas subjetividades.

\section{Referências}

1. Soares BG, Silva BJR. O ambiente estimulador ao desenvolvimento da criança hospitalizada. Rev esc enferm USP. 2008Sep; 42(3):422-429.

2. Ekra EMR, Gjengedal E. Being hospitalized with a newly diagnosed chronic illness - A phenomenological study of children's lifeworld in the hospital. Int J Qualitative Stud Health Well-being 2012; 7(17):18694.

3. Rojas AKA, Machuca RPA. Factores ambientales y su incidencia en la experiencia emocional del niño Hospitalizado. Rev Ped Elec [Internet]. 2009[acesso 2015 mai 19]; I6(1):36-54. Disponível em: http://www.revistapediatria.cl/vol6num1/ pdf/4_FACTORES_AMBIENTALES.pdf

4. Magnabosco G, Tonelli ALNF, Souza SNDH. Abordagens no cuidado de enfermagem à criança hospitalizada submetida a procedimentos: uma revisão de literatura. Cogitare. 2008;13(1):103-8.

5. Ministério da Saúde (BR), Secretaria de Atenção à Saúde. Núcleo Técnico da Política Nacional de Humanização. Ambiência. $2^{a}$ ed. Brasília: Editora do Ministério da Saúde, 2006 [acesso 2015 mai 19]. Disponível em: http://www.saude. sc.gov.br/hijg/gth/Ambi\%C3\%AAncia.pdf 
6. FlickW. Qualidade na pesquisa qualitativa. Porto Alegre: Artmed, 2009.

7. Guizzo BS, Krziminski CO, Oliveira DLLC. O Software QSR NVIVO 2.0 na análise qualitativa de dados: ferramenta para a pesquisa em ciências humanas e da saúde. Rev Gaúcha Enferm.[Internet] 2003[acesso 2015 mai 19];24(1):53-60. Disponivel em: file:///C:/Users/Marina/Downloads/4437-14206-1-PB.pdf

8. Ministério da Saúde (BR). Conselho Nacional de Saúde. Resolução n66. Diretrizes e normas técnicas regulamentadoras de pesquisas envolvendo seres humanos. Brasília, 2012 [acesso 2015 mai 19]. Disponível em: http://bvsms.saude.gov. br/bvs/saudelegis/cns/2013/res0466_12_12_2012.html

9. Gomes ILV, Queiroz MVO, Bezerra LLAL, Souza NPG. A hospitalização no olhar de crianças e adolescentes: sentimentos e experiências vivenciadas. CogitareEnferm.[Internet].2012[acesso 2015 mai 19];17(4):703-9. Disponível em: file://C:/Users/Marina/Downloads/30378-111527-2-PB.pdfm

10. Boff L. O cuidado necessário: na vida, na saúde, na ecologia, na ética e na espiritualidade. Petrópolis:Vozes, 2012.

11. Ryan-Wenger NA, Gardner W. Hospitalized Children's Perspectives on the Quality and Equity of Their Nursing Care. J NursCare Qual 2012;27(1):35-42.

12. Reis LS, SilvaEF, Waterkemper R, Lorenzini E, Cecchetto FH. Percepção da equipe de enfermagem sobre humanização em unidade de tratamento intensivo neonatal e pediátrica. Rev Gaúcha Enferm[Internet]. 2013[acesso 2015 mai 19]; 34(2):118-24. Disponível em: http://www.scielo.br/scielo.php?script=sci_arttext\&pid=S1983-14472013000200015\&lng=en 13. Ferreira NAS, Esmeraldo JD, Blake MT, Antão JYFL, Raimundo RD, Abreu LC. Social representation of the hospital ludic: look of the child. Rev. bras. crescimento desenvolv. hum. [Internet]. 2014[acesso 2015 mai 19];24(2):188-94. Disponível em: http://www.revistas.usp.br/jhgd/article/view/81171/84804

14. Brito LS, Perinotto ARC. O brincar como promoção à saúde: a importância da brinquedoteca hospitalar no processo de recuperação de crianças hospitalizadas. Rev.hosp. [Internet]. 2014[acesso 2015 mai 19];XI(2):291-315. Disponível em: http://www.revhosp.org/ojs/index.php/hospitalidade/article/view/557/578

15. Silva RCC, Oliveira ENB, Chagas MIO, Sousa SMM, Rodrigues TB, Vasconcelos DP.A leitura como método de cuidado humanizado na clínica neurológica pediátrica: um estudo qualitativo. Online braz.j.nurs [Internet].2010[acesso 2015 mai 19];9(2). Disponível em: http://www.objnursing.uff.br/index.php/nursing/article/view/j.1676-4285.2010.3002/677

\section{Juliane Portella Ribeiro}

Endereço para correspondência - Rua: Gonçalves Chaves, $n^{\circ}: 65$,

Bairro: Centro, CEP: 96015-560, Pelotas, RS, Brasil.

E-mail: ju_ribeiro1985@hotmail.com

Lattes: http://lattes.cnpq.br/9222593132496467

Adriane Maria Netto de Oliveira - adrianeoliveira@furg.br

Giovana Calcagno Gomes - giovanacalcagno@furg.br

Maira Buss Thofehrn - mairabusst@gmail.com

Marina Soares Mota - msm.mari.gro@gmail.com

\section{Enviado em 24 de maio de 2016. Aceito em 24 de abril de 2017.}

